Www.jmscr.igmpublication.org

Impact Factor (SJIF): 6.379

Index Copernicus Value: 79.54

ISSN (e)-2347-176x ISSN (p) 2455-0450

crossrefDOI: https://dx.doi.org/10.18535/jmscr/v6i10.59

Journal Of Medical Science And Clinical Research

IGM Publication

An Official Publication of IGM Publication

\title{
Study of Serum Magnesium in Diabetes Mellitus and Correlation with its Microvascular Complications
}

\author{
Authors \\ Sudha.S1, Saritha K Narayanan ${ }^{2}$, M. Ramakrishna Rao ${ }^{3}$, S. Periasamy ${ }^{4}$ \\ ${ }^{1}$ Post graduate, Department of General Medicine, Rajah Muthiah Medical College, Chidambaram Tamilnadu \\ ${ }^{2}$ Assistant Professor, Department of General Medicine, Rajah Muthiah Medical College, Chidambaram, \\ Tamilnadu \\ ${ }^{3,4}$ Professor, General Medicine, Rajah Muthiah Medical College, Chidambaram, Tamilnadu \\ Corresponding Author \\ Dr Saritha.K.Narayanan \\ Email: saritha.narayanan60@gmail.com
}

\begin{abstract}
Aim: The prevalence of diabetes mellitus is on a rising trend. Hypomagnesemia has been reported to occur with increased frequency in patients with type 2 diabetes milletus. It is frequently overlooked and under treated. We aim to study serum magnesium in diabetes mellitus and correlation with its microvascular complications.

Materials and Methods: This is a hospital based prospective study.100 patients with diabetes mellitus were included in this study. The study was done with objective of assessing serum magnesium in diabetic patients and its correlation with microvascular complications such as diabetic retinopathy, nephropathy and neuropathy.
\end{abstract}

Results: Mean age group of our patient was 58.28 \pm 8.35 years. Of the 100 total patients, 40 patients had hypomagnesemia. Maximum number of patients occurred in the age group 55-65 years (42.5\%). 35 patients had diabetic retinopathy. Among them 27 (75.86\%) patients, had hypomagnesemia.14 patients had diabetic nephropathy, out of this13(92.86\%) patients had hypomagnesemia. 4 patients had diabetic neuropathy, among them all (100\%) had hypomagnesemia.

Conclusion: Low serum magnesium levels are commonly seen in diabetic patients. Hypomagnesemia patients had a higher incidence of retinopathy, nephropathy and neuropathy.

Keywords: Diabetes mellitus, serum magnesium.

\section{Introduction}

Diabetic mellitus is a renowned epidemic in the world with nearly $70 \%$ of the people with diabetes live in developing countries. The largest numbers are in the Indian subcontinent (65\% million) and China. Rates of non communicable diseases like diabetes mellitus have risen in the recent decades and are likely to continue as India's population ages and urbanises. The largest numbers with diabetes are in the 40 to 59 age group (132 million in 2010) which is expected to rise further. The prevalence of diabetes has risen from 30 million in 1985 to 382 million in 2013. It is estimated that prevalence may rise to 592 million by the year 2035 according to current trends ${ }^{[1]}$. 
Diabetes mellitus affects multiple organ systems and is a cause or a major risk factor for the majority of the dreadful diseases. Chronic complications of diabetes mellitus are divided as vascular and non-vascular complications. Among vascular complications, micro vascular complications are diabetic specific.

Magnesium is the fourth most abundant cation in the human body and second most abundant intracellular cation ${ }^{[2]}$. It plays an important role in the carbohydrate metabolism. It serves as a cofactor for all enzymatic reactions that require kinases $^{[3]}$. It is a critical element in cellular proliferation and apoptosis and an important cofactor in both cellular and humoral functions ${ }^{[4]}$.

Hypomagnesemia has been reported to occur with increased frequency in patients with type 2 diabetes mellitus, but it is frequently over looked and under treated ${ }^{[5]}$.

The present study was conducted with an objective to evaluate the serum magnesium in diabetes mellitus and correlation with its micro vascular complication such as Diabetic retinopathy, nephropathy and also neuropathy. With a special interest we included the correlation of $\mathrm{HbAlc}$ and its correlation with hypomagnesaemia also in the same study population.

\section{Materials and Methods}

100 patients with diabetes mellitus, irrespective of the age and sex, who were admitted in general medicine ward, were randomly selected based on the following inclusion and exclusion criteria.

\section{Inclusion Criteria}

Patients who gets admitted in general medical ward with Diabetes Mellitus based on history or medical records.

\section{Exclusion Criteria}

1. Chronic diarrhoea (Loose stools more than 4 weeks)

2. Patients with chronic renal failure (based on GFR)

3. Patients on diuretic therapy for more than one month.

4. Patients with history of alcohol abuse as reported by patient or care taker.

From all the patients, detailed history, including the duration and treatment along with clinical examination was carried out. All the findings were recorded in the proforma. Fasting blood sugar, post prandial blood sugar, HbA1c, direct ophthalmoscopy, 24hour urine albumin were measured for all the subjects.

\section{Results}

Statistical method analysis was done using chi square test and sample variable $t$ test to compare proportions. Results were considered significant at $\mathrm{p}$ value $<0.05$.

Table: 1 a -Age Distribution and Magnesium Levels

\begin{tabular}{|l|c|c|c|}
\hline Age (in years) & Percentage & Mean & S.D \\
\hline $45-55$ & 41 & & \\
$56-65$ & 40 & & \\
$66-75$ & 15 & \multirow{2}{*}{58.28} & 8.35 \\
$>75$ & 4 & & \\
\cline { 1 - 2 } Total & 100 & & \\
\hline
\end{tabular}

Table 1-b

\begin{tabular}{|c|c|c|c|c|c|}
\hline \multirow{2}{*}{$\begin{array}{l}\text { Age Group (in } \\
\text { year) }\end{array}$} & \multicolumn{2}{|c|}{ Hypomageneseia } & \multicolumn{2}{|c|}{ Normomagnesemia } & \multirow{2}{*}{$\begin{array}{c}\text { Total } \\
\%\end{array}$} \\
\hline & $\mathbf{N}$ & $\%$ & $\mathbf{N}$ & $\%$ & \\
\hline $45-55$ & 9 & 22.5 & 32 & 53.3 & 41 \\
\hline $56-65$ & 17 & 42.5 & 23 & 38.3 & 40 \\
\hline $66-75$ & 10 & 25.0 & 5 & 8.3 & 15 \\
\hline$>75$ & 4 & 10.0 & - & - & 14 \\
\hline Total & 40 & 100 & 60 & 100 & 100 \\
\hline Chi-square value & \multicolumn{5}{|l|}{16.11} \\
\hline & \multirow{2}{*}{\multicolumn{5}{|c|}{$\begin{array}{l}1 \\
.001 \text { (Significant) }\end{array}$}} \\
\hline 'P' value & & & & & \\
\hline
\end{tabular}




\section{JMSCR Vol||06||Issue||10||Page 344-352||October}

The mean age of the study patients was $58.28 \pm 8.35$ years. In our study maximum number of hypomagnesemia patients occurred in the age group 56 - 65 years (42.5\%). All patients who were more than 75 years old had hypomagnesemia $(100 \%)$. The chi-square test of association is significant $\left(\mathrm{x}^{2}=16.11, \mathrm{p}=.001\right)$ for age distribution and magnesium levels

Table: 1c Age Distribution

\begin{tabular}{|c|c|c|c|}
\hline Parameters & Hypeomagnesemia & Normomagnesemia & Total \\
\hline Mean & 62.20 & 55.67 & 58.28 \\
\hline S.D & 9.29 & 6.52 & 8.35 \\
\hline $\begin{array}{l}\text { 't' value } \\
\text { Df } \\
\text { 'P' value }\end{array}$ & $\begin{array}{l}4.13 \\
98 \\
.001 \text { (Significant) }\end{array}$ & & \\
\hline
\end{tabular}

The Mean age of patients with hypomagnesemia was $62.20 \pm 9.29$ years and it was $55.67 \pm 6.52$ years for Normomagnesemia. There is significant difference in the age between two categories of magnesium levels, calculated by independent sample't' test $(\mathrm{t}=4.13, \mathrm{P}=.001)$.

Chart -1: Age Distribution

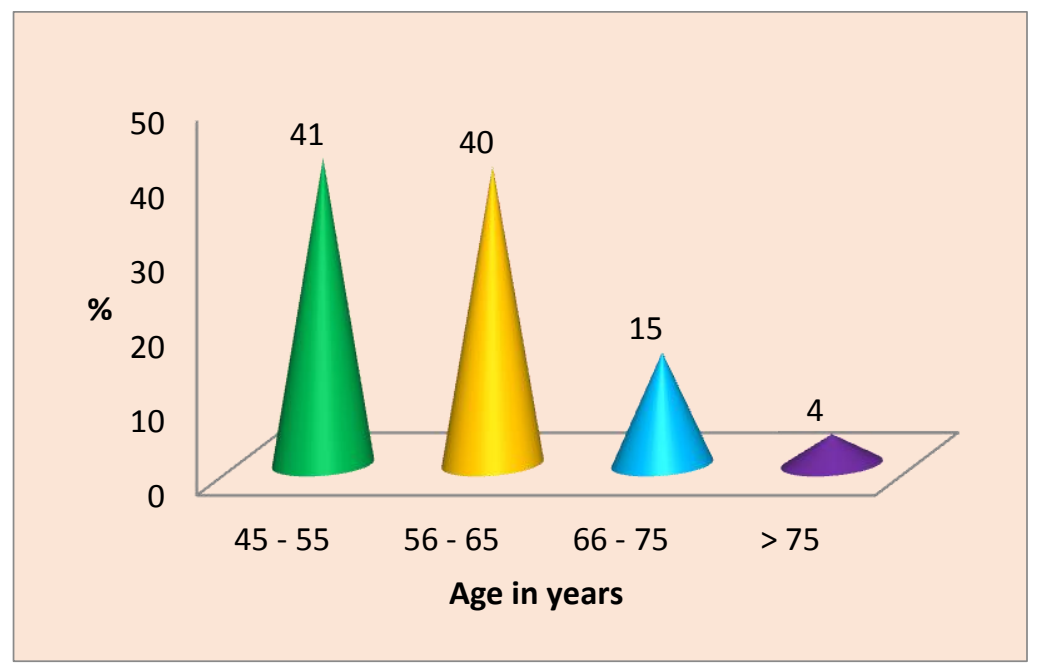

Chart -2: Age Distribution with Hypomagnesemia and Normomagnesemia

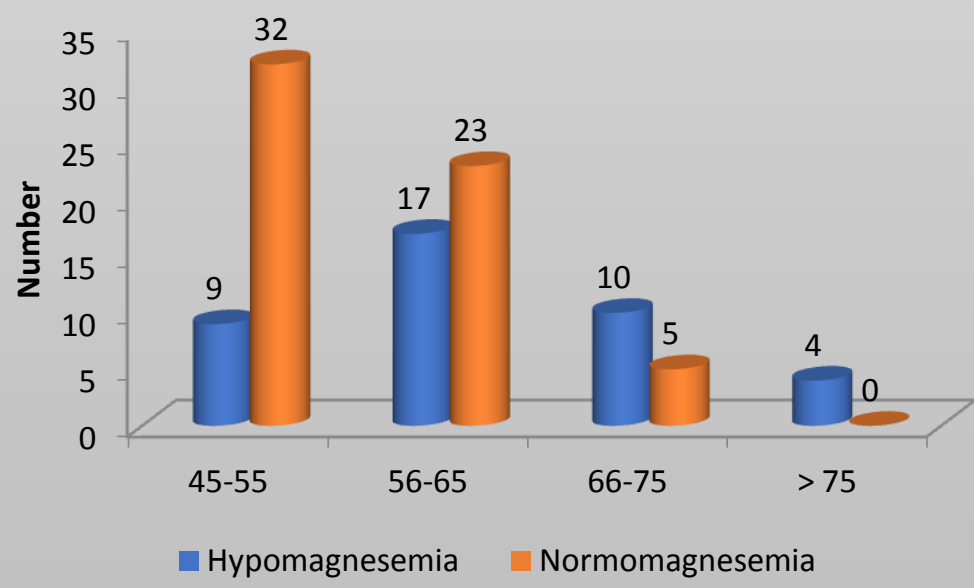


Chart - 3: Prevalence of Hypomagnesemia

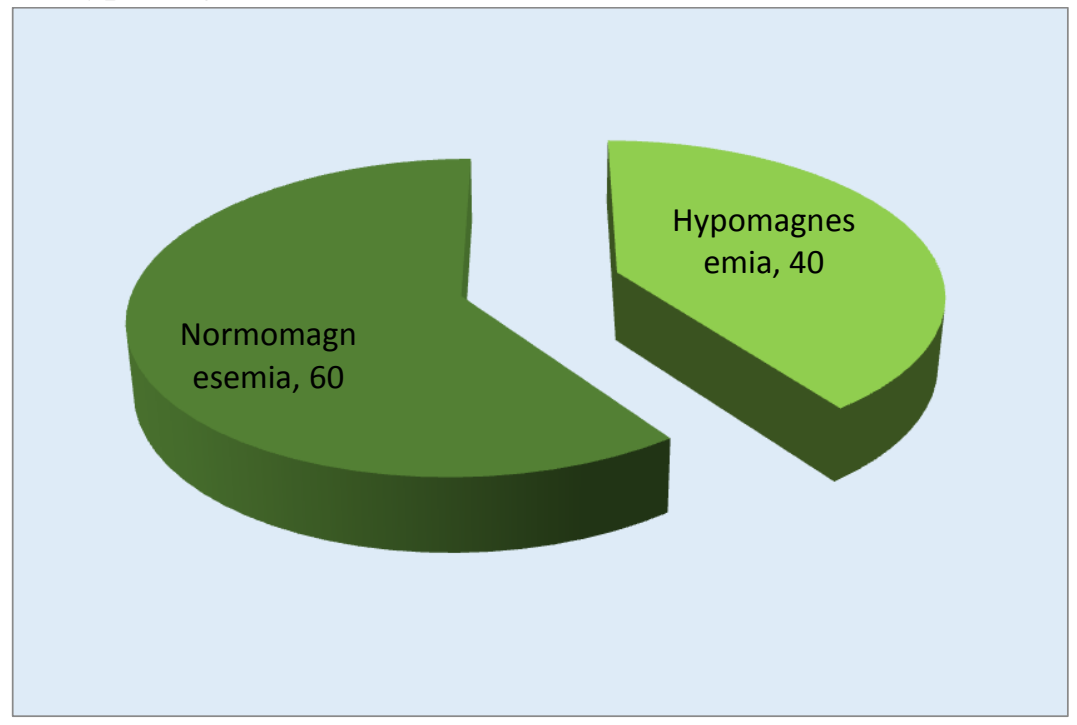

Table: 2a Prevalence of Hypomagnesemia and Neuropathy

\begin{tabular}{|l|c|c|c|}
\hline & No. of Patients & Patients with Hypomagnesemia & Prevalence \\
\hline Neuropathy & 4 & 4 & 100 \\
No Neuropathy & 96 & 36 & 37.5 \\
\hline
\end{tabular}

Chart - 4: Prevalence of Hypomagnesemia and Neuropathy

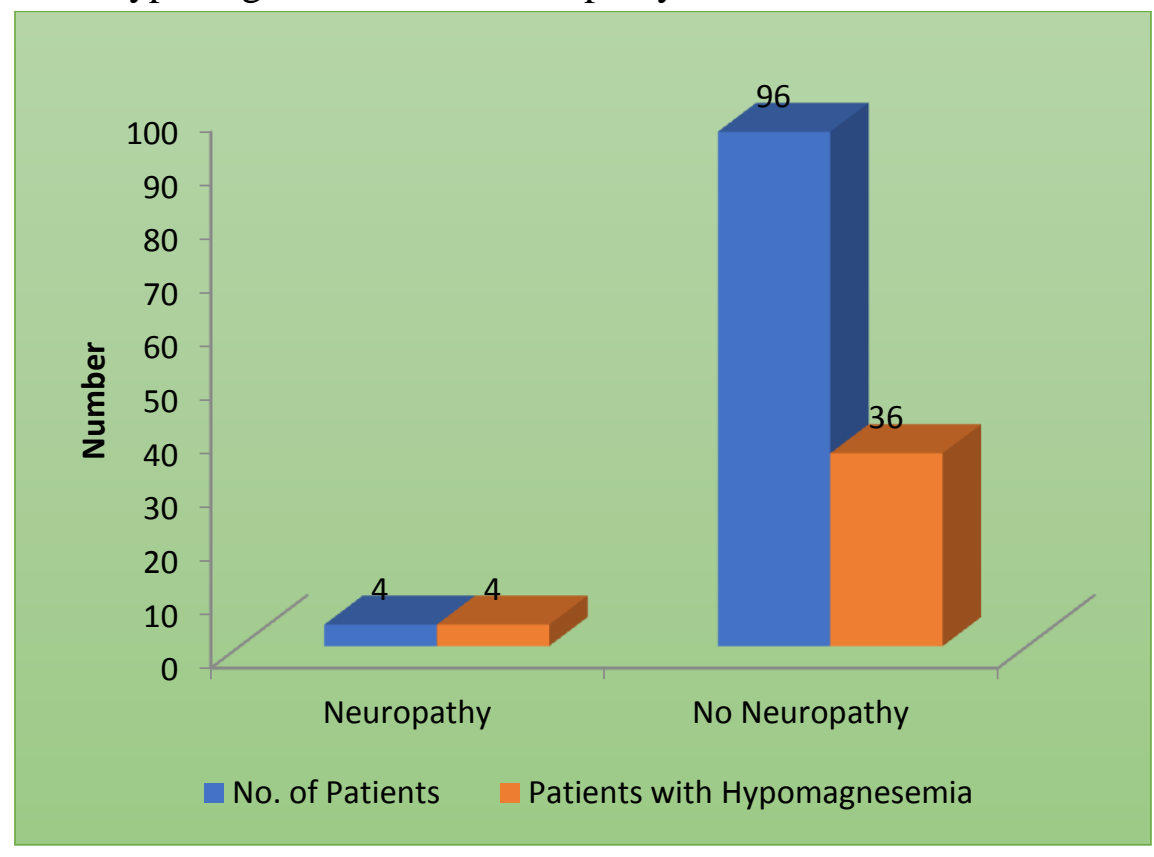

Table 2 b

\begin{tabular}{|l|c|c|c|c|c|}
\hline \multirow{2}{*}{ Neuropathy } & \multicolumn{2}{|c|}{ Hypo magnesemia } & \multicolumn{2}{|c|}{ Normo magnesemia } & Total \\
\cline { 2 - 6 } & $\mathbf{N}$ & $\mathbf{\%}$ & $\mathbf{N}$ & $\mathbf{\%}$ & $\mathbf{\%}$ \\
\hline Present & 4 & 10 & - & - & 4 \\
\hline Absent & 36 & 90 & 60 & 100 & 96 \\
\hline Total & 40 & 100 & 60 & 100 & 100 \\
\hline Chi-square value & & 6.25 & \\
Df & & 1 & \\
'P' value & & .012 (significant) & \\
\hline
\end{tabular}

The prevalance of hypomagnesemia in patients with neuropathy is $100 \%$. The chi-square test of association is significant $\left(\mathrm{x}^{2}-6.25, \mathrm{p}=0.012\right)$. 
Table: 3 a -Hypomagnesemia and Diabetic Retinopathy

\begin{tabular}{|l|c|c|c|}
\hline Retinopathy & $\begin{array}{c}\text { No. of. } \\
\text { Patients }\end{array}$ & $\begin{array}{c}\text { Patients with Hypo } \\
\text { magnesemia }\end{array}$ & Prevalence \\
\hline NPDR & 29 & 22 & 75.86 \\
\hline PDR & 6 & 5 & 83.33 \\
\hline NO Retinopathy & 65 & 13 & 20 \\
\hline
\end{tabular}

Chart - 5: Hypomagnesemia and Diabetic Retinopathy

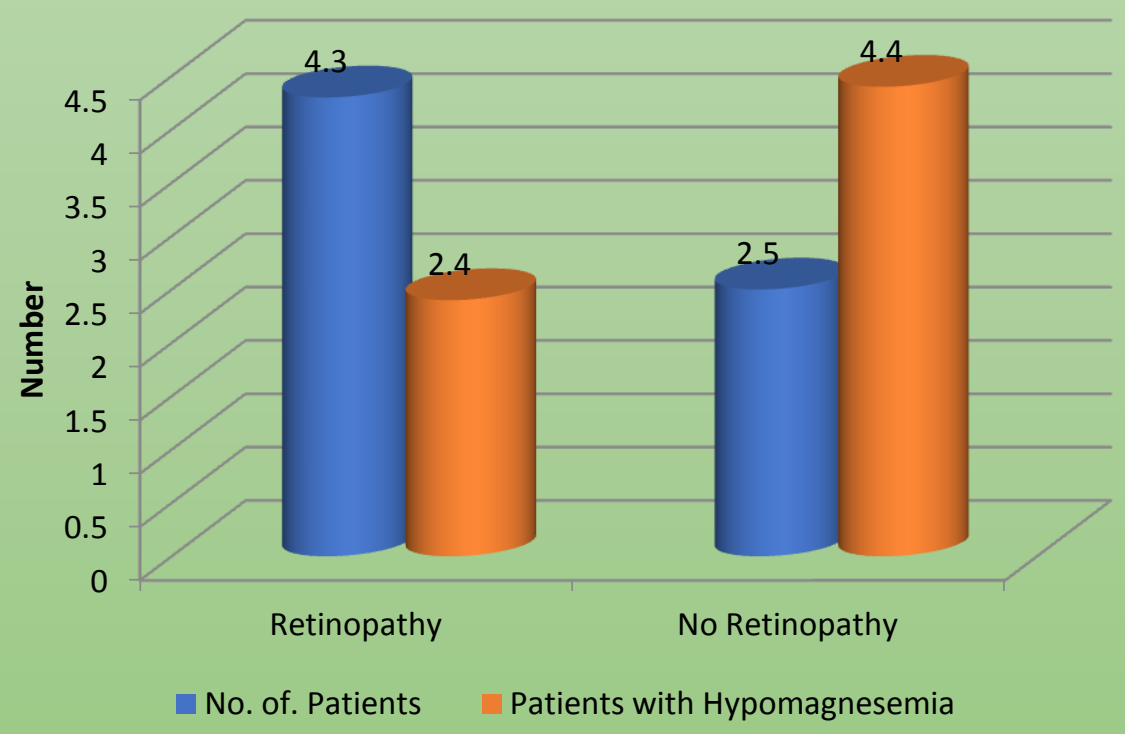

Table 3b

\begin{tabular}{|l|c|c|c|c|c|}
\hline \multirow{2}{*}{ Retinopathy } & \multicolumn{2}{|c|}{ Hypomagnesemia } & \multicolumn{2}{c|}{ Normomagnesemia } & Total \\
\cline { 2 - 6 } & $\mathbf{N}$ & $\mathbf{\%}$ & $\mathbf{N}$ & $\mathbf{\%}$ & $\mathbf{\%}$ \\
\hline Present & 27 & 67.5 & 8 & 13.3 & 35 \\
\cline { 2 - 6 } Absent & 13 & 32.5 & 52 & 86.7 & 65 \\
\hline Total & 40 & 100 & 60 & 100 & 100 \\
\hline $\begin{array}{l}\text { Chi-square value } \\
\text { Df } \\
\text { 'P' value }\end{array}$ & $\begin{array}{l}\text { 30.95 } \\
\text { ling (significant) }\end{array}$ \\
\hline
\end{tabular}

It is inferred from the above table that the hypomagnesemia was observed in $77.14 \%$ of patients with retinopathy. The chi-square test of association is statistically significant $\left(\mathrm{x}^{2}=30.95\right.$, $\mathrm{p}=.001)$.

Observations revealed that out of 100 diabetic patients 35 patients had retinopathy. Among these individuals 27 persons had Low serum magnesium level. Rest of the individuals with retinopathy had normal serum magnesium level using the statistical analysis by chi-square test the association between the presence of Hypomagnesemia with Retinopathy in diabetic patients was found to be significant $(\mathrm{p}=0.001)$.

Table: 4a- Hypomagnesemia and Diabetic Nephropathy

\begin{tabular}{|l|c|c|c|}
\hline Diabetic Nephropathy & No. of. patient & $\begin{array}{c}\text { Patients with } \\
\text { Hypomagnesemia }\end{array}$ & Prevalence (\%) \\
\hline \multicolumn{2}{|c|}{ Nephropathy } & 13 & 92.86 \\
\cline { 1 - 2 } $\begin{array}{l}\text { Micro Albuminuria } \\
\text { Macro Albuminuria }\end{array}$ & 5 & & 31.39 \\
\hline No Nephropathy & 86 & 27 & \\
\hline
\end{tabular}


Chart - 6: Hypomagnesemia and Diabetic Nephropathy

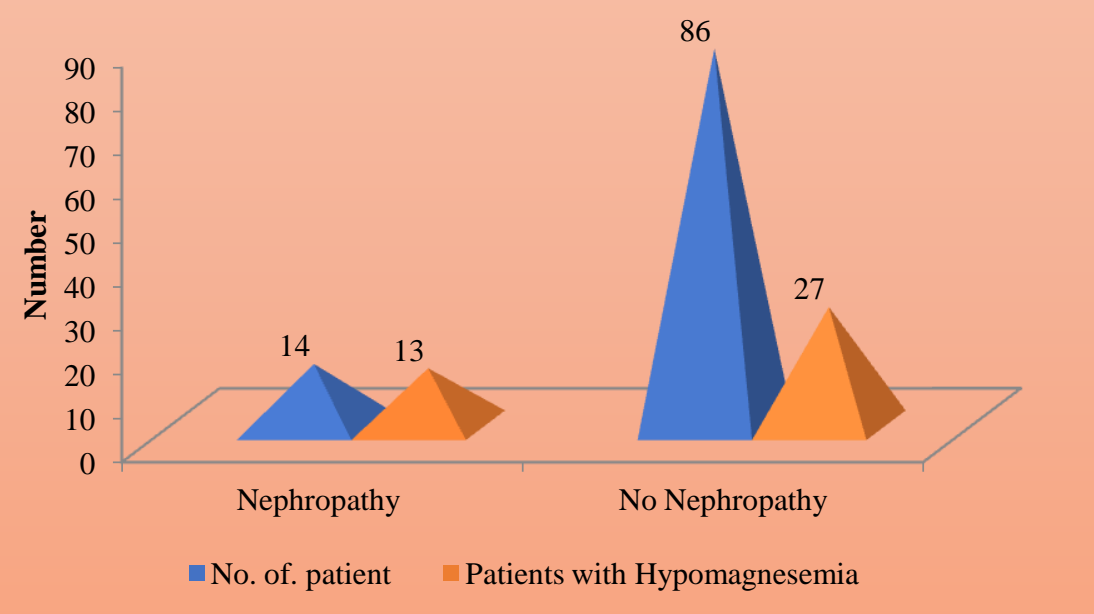

Table 4 b

\begin{tabular}{|l|c|c|c|c|c|}
\hline \multirow{2}{*}{$\begin{array}{l}\text { Diabetic } \\
\text { Nephropathy }\end{array}$} & \multicolumn{2}{|c|}{ Hypomagnesemia } & \multicolumn{2}{c|}{ Normomagnesemia } & Total \\
\cline { 2 - 6 } & $\mathbf{N}$ & $\mathbf{\%}$ & $\mathbf{N}$ & $\mathbf{\%}$ & $\mathbf{\%}$ \\
\hline Present & 13 & 32.5 & 1 & 1.7 & 14 \\
\cline { 2 - 6 } Absent & 27 & 67.5 & 59 & 98.3 & 86 \\
\hline Total & 40 & 100 & 60 & 100 & 100 \\
\hline Chi-square value & & 18.95 & \\
Df & & 1 & \\
'P' value & & .001 (significant) & \\
\hline
\end{tabular}

It our study out of 100 diabetic patients 14 patients had the evidence of nephropathy $(92.86 \%)$ out of these diabetic nephropathy patients 13 patients were low serum magnesium level. Presence of normal serum magnesium level in diabetic nephropathy in our study was low $(1.72 \%)$. Thus the association between the hypomagnesemia and nephropathy in diabetic patient was fond to be statistically significant with the $\mathrm{P}$ value of 0.001 .

Table: 5a- Prevalence of Hypomagnesemia and HbA1C \%

\begin{tabular}{|l|c|c|c|}
\hline HbA1C (\%) & No. of Patient & Patients with Hypo magnesemia & Prevalence \\
\hline$<6$ & 37 & - & - \\
\hline $6-7$ & 29 & 10 & 34.48 \\
\hline $7-8$ & 17 & 16 & 94.11 \\
\hline $8-9$ & 13 & 10 & 76.92 \\
\hline $9-10$ & 4 & 4 & 100.00 \\
\hline
\end{tabular}

Chart - 7: Prevalence of Hypomagnesemia and HbA1C \%

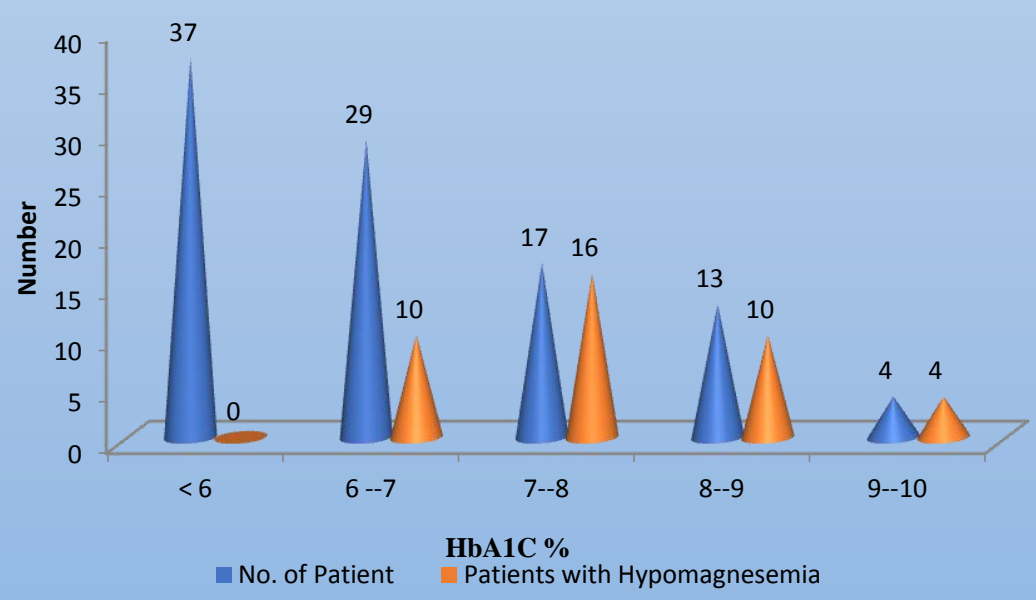


Table 5b

\begin{tabular}{|l|c|c|c|}
\hline & Hypo magnesemia & Normo magnesemia & Total \\
\hline Mean & 7.74 & 5.98 & \multirow{2}{*}{6.69} \\
S.D & .86 & .62 & 1.13 \\
't' value & & 11.93 & \\
\hline Df & 98 & \\
'P' value & & .001 (Significant) & \\
\hline
\end{tabular}

The prevalence of hypomagnesimia is higher when $\mathrm{HbA} 1 \mathrm{C}$ is more 2 vice versa as shown in table 7. The Mean HbA1C was higher in hypomagnesemia $(\mathrm{M}=7.74 \pm .86)$ than in normomagnesemia $(\mathrm{M}=5.98 \pm .62)$. The difference is statistically significant $(\mathrm{t}=11.93, \mathrm{p}=.001)$. In our study Around 34 patient had, poor glycemic control as evidenced by $\mathrm{HbA} 1 \mathrm{C}>7 \%$.

\section{Discussion}

Many studies have proven beyond doubt the association between the presence of hypomagnesemia and diabetes mellitus; it has also been proven that hypomagnesemia has been associated with increased incidence of complications in diabetics; hence I found it worthy to take up this study in our settings.

\section{Diabetes \& Hypomagnesemia}

Previous studies by Rude $\mathrm{RK}^{6}$ have reported low serum magnesium status in patients with type $2 \mathrm{DM}$. The reported prevalence of hypomagnesemia ranged from $13.5 \%$ to $47.7 \%$ in type $2 \mathrm{DM}$ patients according to Pham PC, Pham PM, Miller JM et $\mathrm{al}^{7}$. In our study there were a total of 100 diabetic patients; among them 40 patients had serum $\mathrm{Mg}$ below the reference range; Prevalence of hypomagnesemia in type 2 diabetes mellitus according to our study was similar to that reported by Nadler et $\mathrm{al}^{8}$. Walti $\mathrm{mk}$ et $\mathrm{al}^{9}$ reported that prevalence of hypomagnesemia in type 2 diabetes at $37.6 \%$ versus $10.9 \%$ in non diabeteic controls in a study conducted in, Switzerland; this too is in concordance with our study results;

The causes for the high prevalence of hypomagnesemia in diabetes may be due to increased urinary loss, low dietary intake or impaired magnesium absorption compared to healthy individuals; Mc Nair P, Christiansen MS et $\mathrm{al}^{10}$ in their study found excessive urinary magnesium loss in diabetes. Recently defective tubular reabsorption in thick ascending loop of henle is postulated, that results in hypomagnesemia. The reason for the tubular defect is unclear. In diabetes low serum magnesium status due to low dietary intake is unlikely. Only $5.4 \%$ of the diabetic groups and $9.1 \%$ of the control group in European dietary assessment studies by Walti MK Zimmermann et al ${ }^{11}$ had intake of magnesium below their individual requirements. In addition type 2 diabetes patients with reasonable metabolic control absorb dietary magnesium to a similar extent as healthy controls. In diabetes hyperglycemia and osmotic diuresis may cause excessive urinary loss of magnesium and leads to low serum magnesium status.

\section{Age in Diabetics \& Hypomagnesemia}

In our study maximum number of diabetics occurred in the age group $45-55$ yrs (41 patients); mean age of diabetic patients in our study was 58.28 ; hypomagnesemia occurred maximally in the age group 56-65yrs (42.5\%); all patients who were $>70$ years old were hypomagnesemic $(100 \%)$; mean age of hypomagnesemia in our study was 62.20 years; As the age increased the prevalence of hypomagnesemia increased in diabetics; $p$ value was 0.0001 ; according to Yajinick et $\mathrm{al}^{12}$ and Al Osali ME, Al Qassabi SS et $\mathrm{al}^{13}$ proved a significant correlation between age and magnesium levels; also proved a correlation between the male sex and magnesium levels; our study concurred with the above studies with regards to age but not with sex preponderance and magnesium levels;

\section{HbA1c\% \& Hypomagnesemia}

On analyzing the $\mathrm{HbA1c} \%$ results, we found that 4 patients had values in the range of $9-10 \%$ all 4 of them had hypomagnesemia $(100 \%) 32$ patients had a 
value in the range $7-8 \%$ among them 26 had hypomagnesemia $(94.11 \%)$. Only $34.48 \%$ of the patients who had normal HbA1c values developed hypomagnesemia; the $\mathrm{p}$ value for this association is also 0.001 making it statistically significant. This is similar to the study of Tosiello et $\mathrm{al}^{14}$. Normomagnesemic patients had better control of FBS \& HbA1c than the hypomagnesemia groups; this is well supported by the study done by Prabodh, Prakash et $\mathrm{al}^{15}$.

\section{Diabetic Retinopathy \& Hypomagnesemia}

In the 100 patients we had, 35 patients were found to have retinopathy, among whom 27 had hypomagnesemia (75.86\%); the percentage of hypomagnesemic patients who had retinopathy was $67.5 \%$; the normomagnesemic patients had only $8 \%$ of retinopathy; the $\mathrm{p}$ value indicating the association was 0.0001 which was statistically significant; studies which show similar results as ours are McNair et $\mathrm{al}^{16}$, De walk HV et $\mathrm{al}^{17}$, Hatwal A, Gujral AS et $\mathrm{al}^{18}$.

\section{Diabetic Neuropathy \& Hypomagnesemia}

Only 4 patients had neuropathy but all 4 had hypomagnesemia in our study; hypomagnesemia and presence of neuropathy were statistically correlating as shown by the $\mathrm{p}$ value 0.012 ; Rodriguez morán $\mathrm{M}$ et al showed a correlation between hypomagnesemia and development of neuropathy \& foot ulcer in diabetic patients ${ }^{19}$.

\section{Diabetic Nephropathy \& Hypomagnesemia}

Out of 100, 14 patients had diabetic nephropathy; 13 of the 40 in the hypomagnesemia group had nephropathy (32.5\%) and 1 out of the 60 in the normomagnesemia group had nephropathy (1.7\%). The $\mathrm{p}$ value too supported this association $\mathrm{p}=0.001$. Studies done by Pham PC et $\mathrm{al}^{7}$ and Prakash DS Prabodh $\mathrm{S}$ et al ${ }^{15}$ support this claim; in a study by Corsanello, the explanation for this association was provided for this association; i.e as there is albuminuria in diabetes mellitus, the $30 \%$ of the serum $\mathrm{Mg}$ which is protein bound might be lost more in diabetic nephropathy.

\section{Conclusion}

Low serum magnesium levels are commonly seen in diabetic patients. Hypomagnesemia patients had a higher incidence of retinopathy, nephropathy and neuropathy. A magnesium rich diet consisting of whole grains, legumes, fruits and vegetables such as spinach, okra, dry apricots may be recommended. Long term studies are needed to determine usefulness of magnesium supplementation in the management of type 2 diabetes.

\section{References}

1. Longo, Fanci, Kasper, Hanser, Jameson, Loscalzo, Harrison's principles of internal medicine $19^{\text {th }}$ edition.

2. Pham PC, Pham PM, Pham SV, Miller JM, Pham PT. Hypomagnesemia in patients with type 2 diabetes. Clin J Am Soc Nephrol2007;2:366-73.

3. Saris NEL, Mervaala E, Karppanem H, Khawaja JA, Lewenstam A: Magnesium: An update on physiological, clinical and analytical aspects. Clin Chem Acta 2000; 294: $1-26$.

4. Elamin A, Tuvemo T: Magnesium and insulin dependent diabetes mellitus. Diabetes Res Clin Pract 1990; 10: 203 209.

5. Kao WHL, Folsom AR, Nieto FJ, MO JP, Wtason RL, Brancati FL. Serumand dietary magnesium and the risk for type 2 diabetes: the atherosclerosis risk in communities' study. Arch Intern Med 1999; 159:2151-59.

6. Rude RK,Magnesium deficiency and diabetes mellitus- causes and effects postgrad med J. 1992:92:217-24

7. Pham pc, Pham pm, Pham pa, Pham sv, Pham Hv, miller JM, Yahagawa N, Pham PT. Lower serum magnesium levels are associated with more rapid decline of renal function in patients with diabetes mellitus type 2. clin nephrol 2005 jun 63(6)-42936. 
8. Nadler JC, Rude RK. Disorders of magnesium metabolism. Endocrinal Metab Clinic. North. Am. 1995; 24: 623-41..

9. Walti MK, Zimmermann MB, Spinas GA, Hurrell RF: Low plasma magnesium in type 2 diabetes. Swiss Med Wkly 133:289292, 2003.

10. Mc nair $\mathrm{P}$, Christensen MS, christiansene, madsbad S, Transbol I: Renal hypomagnesaemia in human diabetes mellitus and its relation to glucose homeostasis. Eur I clin Invest 12:8185,1982 .

11. Walti MK, Zimmermann MB, Spinas GA, Hurrell RF: Low plasma magnesium in type 2 diabetes. Swiss Med Wkly 133:289292, 2003.

12. Yajnick CS, Smith RF, Hockaday TDR, Ward NI. Fasting plasma magnesium concentration and glucose disposal in diabetes. BMJ 1984; 288:1032-4.

13. Al. Osali ME, AI - Qassabi SS, EI Sayed MK, Hypomagnesium in type 2 diabets omani patients, Saudi Med J 2009: 30(7) 897-901

14. Tosiello L. Hypomagnesemia and diabetes mellitus. A review of clinical implications. Arch Intern Med. 1996 Jun 10;156(11):1143-8.

15. Prabodh, S. Prakash, DS. Sudhakar, G. Chowdary NV, Desai V, Shekhar R Status of copper and magnesium levels in diabetic nephropathy cases: a case control study from south india, Bio Trall Elemres 2011: 142(1) 29-35

16. Mc Nair P, Christiansen C, Madsbad S, Lauritzen E, Faber $\mathrm{O}$, Binder $\mathrm{C}$ et al. Hypomagnesimia - a risk factor for diabetic retinopathy - diabetics 1978:27:1075-7.

17. De Valk HW Magnesium in diabetes mellitus Neth J Med 1999 APR 54(4)-13946
18. Hatwal A, Gujral A S, Bhatia DP, Agarwal JK, Bajpai HS, Association of hypomagnesenia with diabetic retinopathy - Acta Opthalmol (Copenh) 1989.del: 67(6) 714-6

19. Rodriguez. Moran, M. Guerrero. Romero F, Low serum magnesium levels and foot ulcers in subject with type 2 diabetes, Arch Med Res 2001. Jul-Aug: 32(4): 300-3. 